\title{
Characteristics of Patients Presenting with COVID-19 from Balochistan Province and Lessons Learnt
}

\author{
Abida Munir Badini ${ }^{1}$, Aurangzeb Badini ${ }^{2}$, Naeem M. Mengal ${ }^{3}$ and Kashmira Nanji ${ }^{4}$ \\ ${ }^{1}$ The Aga Khan University Hospital, Karachi, Pakistan \\ ${ }^{2}$ Deputy Commissioner Quetta, Balochistan, Pakistan \\ ${ }^{3}$ National Institute of Cardiovascular Diseases, Karachi, Pakistan \\ ${ }^{4}$ Epidemiologist
}

\begin{abstract}
Objective: With the spread of COVID-19 in Pakistan, Balochistan province with its unique problems of lowest literacy rates in the country, limited resources and a flail health care system is reporting an increasing number of cases of COVID-19. This study discusses the epidemiological and clinical characteristics of COVID-19 patients from the Balochistan province.

Study Design: Situation report

Place and Duration of Study: The study was conducted in Balochistan province of Pakistan. The completion date for the study was April 30, 2020.

Methodology: The data was retrieved from the daily situation report from the Health Department, Government of Balochistan. Descriptive statistics (proportions, mean $\pm \mathrm{SD}$ ) were used for data analysis.

Results: A total of 1136 patients were confirmed to have COVID-19. The highest rate was found in cases with ages $>60$ years. About $78 \%$ of COVID-19 cases were males and majority of the cases (78.56\%)were asymptomatic. Out of these, 183 recovered and 16 died. The case fatality rate was $1.3 \%$.

Conclusion: COVID-19 cases and case fatality ratio is low in Balochistan. Whether this is due to inability to carry out more tests is still to be ascertained. Males and elderly are more affected and fatalities were higher in cases with co-morbid conditions. Balochistan having a weak healthcare system and with the majority of cases being asymptomatic, needs more stringent actions to practice social distancing to avoid further spread of COVID-19.
\end{abstract}

Keywords: COVID-19; pandemic; Pakistan; Balochistan.

How to cite this article: Badini AM, Badini A, Mengal NM, Nanji K. Characteristics of Patients Presenting with COVID-19 from Balochistan Province and Lessons Learnt. J Coll Physicians Surg Pak 2021; 31(JCPSPCR):CR104-CR108.

\section{INTRODUCTION}

A cluster of pneumonia cases of unknown origin were reported in Wuhan, the capital city of Hubei province, China in December 2019. ${ }^{1}$

The causative agent of this pneumonia, a novel corona virus, was isolated after a few days and sequenced, which revealed resemblance to coronavirusessuch as SARS-CoV-14 andMERS-CoV-6 and was labeled SARS-CoV-2 in January $2020 .{ }^{2}$ A disease caused by SARS-CoV-2 was named corona virus disease 2019 (COVI-19) which has spread to 216 countries, infecting a total of $3,090,445$ persons and causing outbreak associated with a new coronavirus of probable bat origin. ${ }^{2,3}$

Correspondence to: Dr. Abida Munir Badini, The Aga

Khan University Hospital, Karachi, Pakistan

E-mail: abida_badini@hotmail.com

Received: June 18, 2020; Revised: January 02, 2021;

Accepted: April 17, 2021

DOI: https://doi.org/10.29271/jcpsp.2021.JCPSPCR.CR104
The disease has attributed to 4,287,961 cases worldwide and the death toll globally due to COVID-19 is 288,318 , as of May 12 , 2020. ${ }^{4}$ COVID-19 can cause mild flu-like symptoms, including fever, cough, dyspnea, myalgia, and fatigue, while the serious form of COVID-19 can cause acute respiratory distress syndrome (ARDS), severe pneumonia, septic shock, and organ failure and can lead to death. ${ }^{2,3}$

The World Health Organization (WHO) announced that COVID-19 should be characterized as a pandemic on March 11, 2020. 4.5 The total number of deaths associated with COVID-19 in Italy, Spain, France, and the United States has exceeded that in China. ${ }^{5}$

In Pakistan, the confirmed number of cases as of May 12, 2020 was 32,674 and the death toll reached to 724 cases, with a case fatality rate of $2.2 \%{ }^{4,5}$ The first case of COVID-19 in Pakistan was confirmed on 26 February, 2020 by the Ministry of Health, Government of Pakistan, in a person who had just returned from Iran. ${ }^{6}$ The disease spread to Iran, the neighboring country of Pakistan, from where it had spread quickly to Pakistan owing to the thousands of pilgrims who entered from Iran to Pakistan via Balochistan province. 
Balochistan received 3000 pilgrims from Iran and kept them in quarantine center at Taftan in the first week of March, 2020; the numbers later exceeded 6000. The first case of COVID-19 in Balochistan was reported on March 10, 2020. ${ }^{7}$ As of the current situation, the number of confirmed cases in Balochistan is 2061 (May 12, 2020), while the death toll is $27 .^{8}$

Pakistan is a middle to low income country with a weak health care delivery system. However, the response by the Pakistan government has been commendable to the global COVID-19 crisis. Balochistan could have been at the center of the coronavirus outbreak as a result of the quarantine crisis at Taftan. However, the Government of Balochistan took a timely decision and started screening of all people crossing the borders, establishing quarantine centers, followed by closure of all educational institutes and later a lockdown in the province.

The objective of this study was to find out the characteristics of patients presenting with COVID-19 in Balochistan, including brief comment on the epidemiology and clinical features. This study also discusses emerging COVID-19 pandemic based on the currentevidence.

\section{METHODOLOGY}

Situated in southwest of Pakistan, Balochistan province borders Afghanistan and Iran in the west and the Arabian Sea in the south. It accounts for nearly half of Pakistan's land mass and is immensely rich in natural resources, including oil, gas, coal, copper and gold. According to 2017 census data, the population of Balochistan is 12.34 million with $6,483,653$ males and $5,860,646$ females. $^{9}$

The study was designed as a situation report. The data was retrieved from the official daily situation report from the Health Department of Government of Balochistan. The data consisted of 9821 subjects who were suspected of having COVID-19 based on their history of travel, exposure to a persons having COVID-19, or having any of the symptoms of COVID-19,i.e., fever, cough, sore throat or shortness of breath. The data included subjects from all districts of Balochistan. Nasal or throat swab for COVID-19 PCR tests were conducted for confirmation of having COVID-19. The completion date for the study was April 30, 2020.

A written permission was taken from the Health Department of Balochistan for use of the data for this study.

Statistical analysis was carried out using SPSS software (Statistical Package for the Social Sciences, version 19). Mean and standard deviation was reported for age and proportions were calculated for all other indicators. Case positivity rate was calculated by dividing confirmed COVID cases by number of tests conducted. Age-specific COVID-19 cases and attack rate was reported. Attack rate was calculated by dividing the number of COVID-19 cases in the specific age group by number of population in the specific age group per $1,000,000$ population. Case fatality rate (CFR) was calculated by dividing number of deaths by COVID-19 with number of diagnosed COVID-19 cases.

\section{RESULTS}

Screening of 26,220 people was done in Balochistan by the health department. For the 15,335 suspected cases, 9,821 tests were conducted for confirmation of COVID-19. A total of 1,136 patients were confirmed to have COVID-19, while 8,685 people tested negative for the disease. The COVID-19 positivity rate was $11.56 \%$. From the above 1,136 patients, 183 patients recovered and 16 died of COVID-19 in Balochistan. The active cases from Balochistan were 937 (Figure 1).

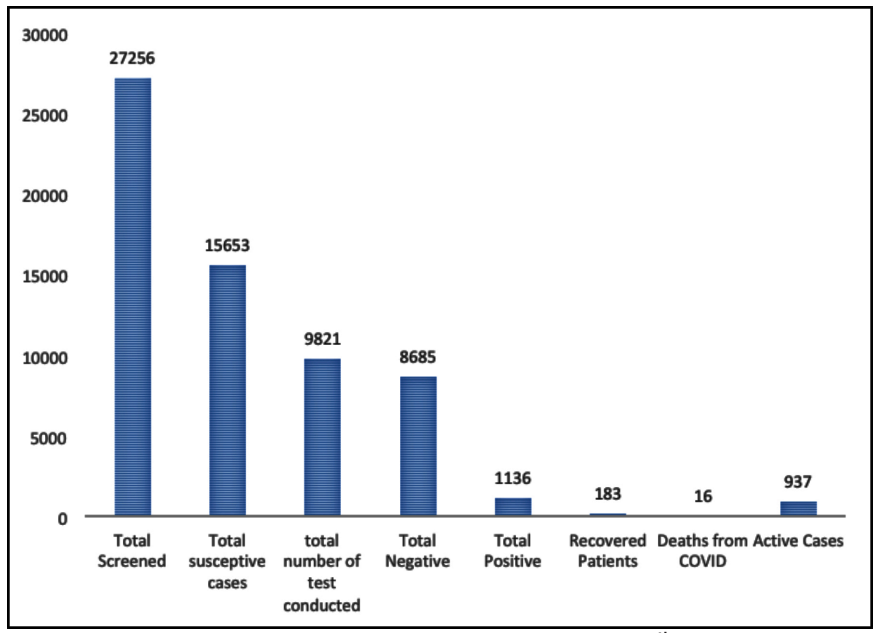

Figure 1: COVID-19 Case Details in Balochistan (April 30 ${ }^{\text {th }}, 2020$ ).

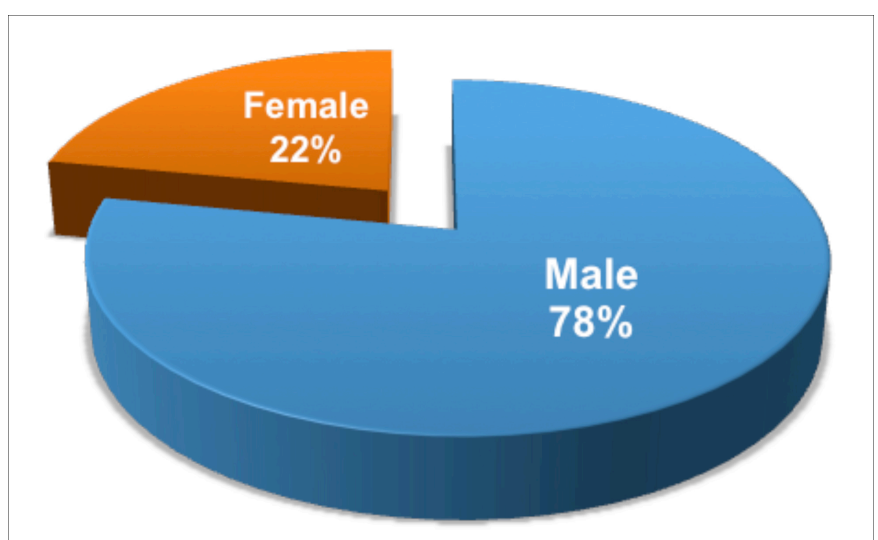

Figure 2: Gender Based Distribution of COVID-19 Cases in Balochistan.

The majority, 770 (93.2\%), of the cases were from Quetta, the capital city of Balochistan province, followed by small percentagesfrom other districts surrounding Quetta.

District wise, the attack rate/1,000,000 population was highest in Quetta (353) too, followed by Pishin (64), Sibi (62) and Khuzdar (60).

In Quetta city, the highest attacke rate was reported in the union council Marriabad (UC 6,7) where most people travelling to Iran resided.

The mean age of the cases was 35 years, with the age range of minimum of 2 months to maximum of 94 years. The most affected age group was $30-44$ years $(n=353: 33.84 \%)$ followed by $15-29$ years $(n=277: 26.07 \%)$. The highest attack rate $(278 / 1,000,000$ population) was reported in the age group $60+$ years, followed by 
45-59 years age group (205/1,000,000 population). The overall attack rate was 74/1,000,000 population in the Province (Table I).

Table I: Age-specific COVID-19 Cases and attack rate in Balochistan (April 30,2020 ).

\begin{tabular}{|l|c|c|c|c|}
\hline Age groups & $\begin{array}{c}\text { Number of } \\
\text { confirmed } \\
\text { cases }\end{array}$ & Percentage & $\begin{array}{c}\text { Population } \\
\text { in age group }\end{array}$ & $\begin{array}{c}\text { Attack } \\
\text { rate/1000000 }\end{array}$ \\
\hline $\begin{array}{l}<1-14 \\
\text { years }\end{array}$ & 93 & $8.90 \%$ & 6715115 & 14 \\
\hline $\begin{array}{l}15-29 \\
\text { years }\end{array}$ & 277 & $26.51 \%$ & 2832969 & 98 \\
\hline $\begin{array}{l}30-44 \\
\text { years }\end{array}$ & 353 & $33.78 \%$ & 2462510 & 143 \\
\hline $\begin{array}{l}45-59 \\
\text { years }\end{array}$ & 195 & $18.66 \%$ & 884338 & 221 \\
\hline 60 or more & 84 & $8.04 \%$ & 295446 & 284 \\
\hline Unknown & 43 & $4.11 \%$ & & 79 \\
\hline Total & 1045 & $100 \%$ & 13190378 & 79 \\
\hline $\begin{array}{l}\text { ^Population of Districts are taken from 2017 censes and population of } \\
\text { year 2020 was calculated with growth rate of 2.6. }\end{array}$ & \multicolumn{5}{|l}{} \\
\hline
\end{tabular}

Table II: Clinical pattern of disease of COVID-19 patients in Balochistan.

\begin{tabular}{|l|c|c|}
\hline Clinical picture & Number of cases & Percentage \\
\hline Asymptomatic & 821 & $78.56 \%$ \\
\hline Fever & 139 & $13.30 \%$ \\
\hline Cough & 106 & $10.14 \%$ \\
\hline Runny nose & 29 & $2.78 \%$ \\
\hline Body ache & 69 & $6.60 \%$ \\
\hline Head ache & 43 & $4.11 \%$ \\
\hline Sore throat & 36 & $3.44 \%$ \\
\hline Rigors & 2 & $0.19 \%$ \\
\hline Shortness of breath & 31 & $2.97 \%$ \\
\hline No Information on symptoms & 57 & $5.45 \%$ \\
\hline \$ Individual symptoms sum cannot be 100\% \\
\hline
\end{tabular}

It was reported that $78 \%(n=817)$ of patients with COVID-19 were males while 22\% ( $n=228)$ were females (Figure 2$)$.

Of the cases found to be positive, $13.78 \%(n=144)$ had a history of international travel while local transmission accounted for $86.22 \%(n=901)$.

Majority of the patients (78.56\%)who were tested positive for COVID-19 were reported to be asymptomatic. Approximately, $13.30 \%$ presented with fever, $10.14 \%$ with cough, $6.60 \%$ had body aches, and $3.44 \%$ sore throat.Shortness of breath was reported to be among $2.97 \% .2 .7 \%$ had runny nose.Rigors were present in $0.19 \%$ and $5.45 \%$ of the patients didnot have any information of symptoms (Table II).

The mean duration of hospitalizationor test negativitywas recorded as 19 days with a range of 7 to 27 days.

The total number of people who died of COVID-19 in the province were 16, mostly due to co-morbid conditions associated with COVID-19. The fatalities reported from COVID-19 were associated with; hypertension and diabetes $(n=6), \operatorname{ARDS} / \operatorname{COPD}(n=4)$, renal failure $(n=3)$, and carcinoma $(n=1)$. The CFR was calculated to be $1.3 \%$ in Balochistan. The recovery rate of positive cases was $16 \%$ $(n=183)$.

\section{DISCUSSION}

COVID-19 has rapidly spread all across Pakistan. Balochistan province, has reported fewer cases compared to other densely populated provinces of Pakistan.

One factor could be the lower testing capacity of Balochistan compared to other provinces of Pakistan. ${ }^{10}$ The authors are of the view that the total number of COVID-19 cases is likely to be higher but under reported due to the difficulties in identifying and reporting of mild and asymptomatic cases present in the community.

The positivity rate was reported to be $11.59 \%$ in Balochistan province, which is higher than that reported in some countries like India and South Korea (2.6\% and $2.7 \%$, respectively) but lower than countries like Italy (19.8\% as of $20^{\text {th }}$ March, 2020) and Spain etc. ${ }^{11,12}$ South Korea has adopted the approach of doing community testing, thus yielding lower positivity rates.Italy, on the other hand, carried out testing on the symptomatic and severe cases, which might have resulted in a higher positivity rate.

While the main affected group was the younger age group (30-44 years), the attack rate was reported to be highest in the elderly (60+ year group). This could be worrying as international studies have shown poor clinical outcomes associated with olderage and underlying co-morbidities. ${ }^{13}$

Comparable to international studies, females and children were less affected by COVID-19 in Balochistan. ${ }^{14}$ This could be due to the fact that in some provinces of Pakistan, males are the sole bread earners and usually go out of homes for work. The reports from China and Italy indicate that females and children are underrepresented, especially among severe and fatal cases. ${ }^{15,16}$ It isstill not known whetherthis is because of less exposure, or because they are less likely to show symptoms or are lesslikely to get infected.

In contrast to previous studies, the majority of patients with COVID-19 in Balochistan were asymptomatic. ${ }^{17,18}$ This could be problematic, as the asymptomatic patients will continue to infect more people without being detected. Another study conducted in Iceland reported that $43 \%$ of the participants who tested positive reported no symptoms. ${ }^{19}$

The CFR reported in Balochistan is lower than many countries. Italy has a CFR of 13.59, Spain 11.40, Germany 3.9, India 3.2, and Iran 6.3, (as of $30^{\text {th }}$ April, 2020). Singapore, on the other hand, had a CFR of $0.09 .^{5}$ The recovery rate of positive cases in the province was $16 \%$.

Many factors can confound the estimation for CFR and recovery rate, such as, undetected cases or delayed case reporting can significantly affect the CFR and recovery rate and thus it has to be interpreted with caution. More research is needed to ascertain into these factors.

Mortality fromCOVID-19 was associated with co-morbids like hypertension and diabetes in Balochistan. International data 
also show mortality in COVID-19 to be higher in patients with underlying health conditions. ${ }^{14,18}$

Government of Balochistan has adopted unprecedented measures to limit the spread of the virus and flatten the curve. These measures include starting screening process, establishment of quarantine centers, closing borders with neighboring countries, closing educational institutions, imposing ban on public gatherings and implementing province-wise lockdowns. However, since the report shows the transmission to be local and the cases to be asymptomatic in the area, if strict social distancing is not practiced, the numbers could rise exponentially and the healthcare system will not be able to effectively handle the burden.

Due to the shortage of COVID-19 testing kits, we recommend that the criteria of clinically diagnosed cases based on the history of exposure, clinical symptoms and typical X-ray chest (CT chest imaging if available) should be used to detect, isolate and monitor suspected cases, thus limiting the spread, while reserving the healthcare facilities for the more severe cases.

It is strongly recommended that medical supplies, including personal protective equipments (PPEs), should be provided to hospitals at district level to aid the healthcare providers in dealing with the ever increasing cases of the COVID-19 pandemic. Besides this, invasive equipment including ventilators should be provided to divisional headquarter hospitals/ teaching hospitals of the medical colleges, so that the coming burden of severe cases can be decreased on the tertiary care hospital of the main cities.

COVID-19 has posed huge challenges to countries with inadequate healthcare infrastructures and lack of preparedness to deal with such pandemic. Weak infrastructure and financial constraints in Pakistan are the major factors hindering response to the current pandemic. So, the government should make liaison with private sectors to invest in public health interventions.

Stringent policies for the implementation of public health measures should be taken to prevent transmission of COVID-19 including wearing mask, hand washing and social distancing, etc.

Researches should be carried out to assist the government in shaping up COVID-19 policies.

Though the National, Provincial and District Disaster Management Authorities and the key players at the federal and provincial levels are working meticulously to address the pandemic issue but international communities must come forward to help the third world countries like Pakistan to help them come out of this pandemic.

\section{CONCLUSION}

COVID-19 pandemic has challenged the healthcare system of every country and Pakistan being a low to middle-income country, is facing a massive task in addressing this issue.
Currently, the virus has not yet been contained and the most terrifying situation may arise with the surge of seriously ill patients requiring intensive care and ventilators. However, on a positive side, this pandemic has given us the opportunity to indeed strengthen our healthcare delivery system. Multi-sectoral interventions are required to address this public health emergency.

\section{ACKNOWLEDGEMENT:}

The completion of this study would not have been possible without the assistance and participation of so many people whose names may not all be numerated. The contributions are sincerely appreciated and gratefully acknowledged.However the group would like to express their deep appreciation to the following:

The Health Department, Govt. of Balochistan.

Dr. Saleem Abro. Director General Health Services Provincial Health Directorate, Quetta-Balochistan.

Dr. Sarmad Khan. COVID-19 Operational Cell, Quetta, Balochistan.

\section{PATIENTS' CONSENT:}

A written permission was taken from the Health Department Government of Balochistan to use the data. It was not an active data collection and all the personal identifiers of the patients were removed from the study.

\section{CONFLICT OF INTEREST:}

Authors declared no conflict of interest.

\section{AUTHORS' CONTRIBUTION:}

AMB: Conception and design, drafting, final approval.

$A B$ : Data acquisition and analysis, final approval. NMM: Drafting, critical revision, final approval.

$\mathrm{KN}$ : Analysis and interpretation, critical revision, final approval.

\section{REFERENCES}

1. Huang C, Wang Y, Li X, Ren L, Zhao J, Hu Y, et al. Clinical features of patients infected with 2019 novel coronavirus in Wuhan, China. Lancet 2020;395(10223):497-506. doi: 10.1016/S0140-6736(20)30183-5

2. Zhou P, Yang X-L, Wang X-G, Hu B, Zhang L, Zhang W, et al. Molecular and serological investigation of 2019-nCoV infected patients: implication of multiple shedding routes. Emerg Microbes Infect 2020;9(1):386-389. doi: 10.1080/ 22221751.2020.1729071.

3. Zhang W, Du R-H, Li B, Zheng X-S, Yang X-L, Hu B, et al. A pneumonia outbreak associated with a new coronavirus of probable bat origin. Nature 2020;579(7798):270-273. doi: 10.1038/s41586-020-2012-7.

4. World Health Organization. Coronavirus disease (COVID-19) pandemic. 2020 [Internet]. Available from:http://www. who.int/ emergencies/diseases/novel-coronavirus-2019 [cited May 5, 2020].

5. World Health Organization. Coronavirus disease (COVID-2019) situation reports. 2020 [Internet]. Available from:http://www.who.int/emergencies/diseases/novel-coron avirus-2019/situation-reports[cited May 10, 2020.]

6. Gul A. Pakistan Detects First Coronavirus Cases, Links to 
Iran Outbreak. VoA 2020 [Internet]. Available from: http://www.voanews.com/science-health/coronavirus-outbr eak/pakistan-detects-first-coronavirus-cases-links-iranoutbreak[cited May 09, 2020].

7. GEO TV. "Coronavirus updates: Latest news on the coronavirus outbreak from Pakistan and around the world". 2020.

8. Government of Pakistan. COVID-19 Cases in Pakistan [Internet]. Available from: http://covid.gov.pk/stats/ pakistan [cited May 12, 2020].

9. Pakistan Beaurau of Statistics GoP. Province-wise Population By Sex And Rural/Urban Census: 2017. Pakistan. 2017 [Internet]. Available from: http://www.pbs.gov.pk/ sites/default/files/DISTRICT_WISE_CENSUS_RESULTS_CENSU S_2017.pdf [cited 10 October, 2020].

10. UN Office for the Coordination of Humanitarian Affairs. Pakistan: COVID-19 - Situation Report As of 30 April 2020 [Internet]. Available from: http://reliefweb.int/report/ pakistan/pakistan-covid-19-situation-report-30april-2020[cited May 03, 2020].

11. Chakrabarti SS, Kaur U, Banerjee A, Ganguly U, Banerjee T, Saha S, et al. COVID-19 in India: Are Biological and Environmental Factors Helping to Stem the Incidence and Severity? Aging Dis 2020:11(3):480-488. doi: 10.14336/ AD.2020.0402.

12. Elflein J. Number of coronavirus (COVID-19) tests performed in the most impacted countries worldwide as of May 8, 2020. [Internet]. Available from: http://www.statista.com/ statistics/1028731/covid19-tests-select-countriesworldwide/ [cited May 10, 2020].
13. Chang D, Lin M, Wei L, Xie L, Zhu G, Cruz CSD, et al. Epidemiologic and clinical characteristics of novel coronavirus infections involving 13 patients outside Wuhan, China. JAMA 2020;323(11):1092-1093. doi: 10.1001/jama. 2020.1623.

14. Remuzzi A, Remuzzi G. COVID-19 and Italy: what next? Lancet 2020;395(10231):1225-1228. doi: 10.1016/ S0140-6736(20)30627-9.

15. Guan W-j, Ni Z-y, Hu Y, Liang W-h, Ou C-q, He J-x, et al. Clinical characteristics of coronavirus disease 2019 in China. N Engl J Med. 2020;382(18):1708-1720. doi: 10.1056/NEJMoa2002032.

16. Onder G, Rezza G, Brusaferro S. Case-fatality rate and characteristics of patients dying in relation to COVID-19 in Italy. JAMA 2020; 323(18):1775-1776. doi: 10.1001/ jama.2020.4683.

17. Wu Z, McGoogan JM. Characteristics of and important lessons from the coronavirus disease 2019 (COVID-19) outbreak in China: summary of a report of 72314 cases from the Chinese Center for Disease Control and Prevention. JAMA 2020;323(13):1239-1242. doi: 10.1001/jama.2020.2648.

18. Li X, Xu S, Yu M, Wang K, Tao Y, Zhou Y,et al. Risk factors for severity and mortality in adult COVID-19 inpatients in Wuhan. J Allergy Clin Immunol2020;146(1):110-118. doi: 10.1016/j.jaci.2020.04.006.

19. Gudbjartsson DF, Helgason A, Jonsson H, Magnusson OT, Melsted P, Norddahl GL, et al. Spread of SARS-CoV-2 in the Icelandic population. N Engl J Med 2020; 382(24): 2302-2315. doi: 10.1056/NEJMoa2006100. 